REPORT OF A CASE OF
EXTENSIVE FRACTURE AND DISLOCATION
OF THE BONES OF THE FACE.

BY Dr. FYFFE, 5 th Dragoon Guards,

DR. F. J. HENSLEY.

LIEUT. $\mathrm{K}$ - - on returning in a four-wheeled cab to Whitehall-gardens from a dinner-party, late on the evening of the 29 th of May, 1860, met with the following accident:-

$\mathrm{He}$ had ordered the cabman to drive to the National Club, but, by some mistake, the driver passed the entrance into Whitehall-gardens, and went on until he had nearly reached the end of Parliament-street.

Mr. $\mathrm{K}-$, who had been half asleep in the cab, perceiving the driver's mistake, rose from his seat, and ordered the man to return to Whitehall-gardens. In giving the order Mr. Kleaned with his head and the upper part of his body out of the window; the cabman wheeled rapidly round while $\mathrm{Mr} . \mathrm{K}-$ remained in that position, but, in the act of turning, the cab fell over; the back part of Mr. K_-'s head came in contact with the pavement, and the body of the cab fell directly upon his face.

As soon as assistance could be procured, he was conveyed to the Westminster Hospital, and was placed in a ward by him. self. At first he was quite insensible, but in about an hour he was able to articulate the words "Dr. Fyffe, 5th Dragoon Guards, National Club."

I was telegraphed for from Brighton, and arrived at 11 o'clock on the forenoon of the $30 \mathrm{th}$. On my arrival I found Mr. $\mathrm{K}-$
in the following condition :- Head and face immensely swollen in the following condition:- - Head and face immensely swollen that it was scarceiy possible to recognise them; a deep contused wound, about an inch and a half in length, existed above the left eyebrow, and a smaller one on the bridge of the nose. On making an examination of the injuries a perpendicular fracture was discovered through the boly of the lower maxillary bone, a little to the left of the mesial line. Two fractures were also discovered in the superior maxillary bones, about an inch on either side of the mesial line; the bones of the nose were also found to be fractured. Owing to the great swelling no further injuries could be discovered at this time.

These injuries were accompanied, at first, by insensibility, from which he began to recover in a few hours; he then romited a large quantity of partially coagulated blood, the result of hæmorrhage from the posterior nares. He spoke with great difficulty and indistinctuess, and did not complain of pain. Pulse 80, weak and irregular. Cold applications were used to the head and face, a mould of gutta percha was placed under the lower jaw, supported by a bandage, and he was fed with arrowroot and wine from a feeder with a small aperture. While he remained in the Westminster Hospital he was, of course, under the care of the medical officers of that institution, and received from them every attention. Delirium supervened on the second night; he was, occasionally, very wild, tore off the bandages and dressings, and tried to jump out of bed; but it was a form of delirium very easily restrained. A few quiet but firm worda generally succeeded in persuading him, without using any restraint, to return to his bed. These symptoms continued, almost nightly, during the five days he remained in the hospital. Opiates were freely administered, and sometimes with good effect; his diet was nourishing, and wine was given daily. The swelling of the face diminished rapidly, and on the 4th of June, after consultation with Dr. Hensley and one of the surgeons of the hospital, he was removed to Dr. Hensley's house, No. 5, Spring gardens.

His symptoms were rather increased by the moving, although it was carefully done in an invalid carriage. His pulse in. creased to 120 ; delirium again supervened, and was more violent in character; he talked incessantly in his partial sleep, although quite conscious when awake; the pupils were natural.

June 5th. - Delirium somewhat less violent; does not complain of pain; pulse 115 , low and weak. Ordered half a drachm of Battley's sedative every night, and the following diet-A cup of coffee, with an egg beaten up in it, in the morning; a breakfast cup of beef tea, made from the essence
prepared by Fortnum and Mason, three times in the twentyfour hours; also arrowroot, with an ounce of brandy, thrice in
the twenty-four hours.

On the 6th of June a consultation was held with Mr. Fergusson, and by this time the swelling had so far subsided as to enable us to ascertain the extent of the injuries, and it was discovered that, in addition to the fractures in the lower and upper maxillary and nasal bones already mentioned, both malar bones were loose and separated from their attachments, and that the left malar bone was fractured through that portion of it which forms the lower rim and floor of the orbit, the fractured ends being slightly tilted upwards, forming a small sharp prominence. A small fracture was also found at the external angular process of the frontal bone on the left side; every one of the external bones of the face seemed more or less to have suffered injury. How far the injuries discovered extended internally it was difficult to say, but from the profuse purulent discharge which began to be poured into the mouth, there could be little doubt but that some of the deeperseated bones were injured also. It was remarkable to observe how movable the bones of the face were. On watching the patient's profile, while he was in the act of swallowing food, the whole of the bones of the face were observed to move up and down upon the fixed part of the skull as the different muscles were brought into motion; it appeared as if the integuments only retained them in their position. It was a curious feature in the case that notwithstanding the very extensive injury done, and the violent character of the force which caused them, not a single tooth was fractured or misplaced.

At Mr. Fergusson's suggestion the fractured portions of the superior maxillary bones were bound together with silver wire passed round the teeth. An attempt was made to fasten wire round the teeth of the lower jaw in the same manner, but, from the inclination of the teeth towards the mesial line, great difficulty was experienced in making the wire fast, and, after many trials, it was given up. The gutta percha splint or mould was kept still under the lower maxilla, and strict silence was enjoined.

7th.--Slept a little during the night; was often delirious and excited; face flushed; complains of headache; pulse 106. Half an onnce of castor oil to be taken immediately; twentyfive minims of Battley's sedative solution at night.

8th.-Mr. Tomes was called in to meet Mr. Fergusson, Dr. Hensley, and myself. He took a mould of the lower jaw in gutta percha from the inside of the month. We were now obliged to remove the gutta percha splint from underneath the $j * w$, owing to the formation of a small abscess opposite to the point of fracture.

9th. - Bowels were freely moved; passed a better night; pulse 84 . Mr. Tomes met us again and brought with him a cast of the lower maxilla in plaster of Paris, upon which he had fitted a silver plate, or mould, lined with the pink gutta percha used by dentists. Heating this and pressing it down over the teeth, it fitted accurately; the teeth were thus firmly imbedded in the gutta percha, which, being covered again with the silver plate, prevented any motion between the fractured ends of the bone. The comfort of this adjustment of the fracture was at once felt by the patient; he could now take his food easily and without pain, and he could speak freely without displacing the fracture.

15th.- There has been very little return of the delirinm; he continues to take food very well; not so much motion of the bones of the face in the act of swallowing; swelling has almost e tirely subsided; a good deal of discoloration still exists; no union, as yet, between the fractured bones.

17th. - Allowed to sit up. The abscess under the chin has been opened. Strength very much improved; wounds on the forehead are now healing.

On the 28th Mr. K - was able to go out for a drive in a carriage. Union was evidently taking place in the upper jaw, but in the lower maxilla there has been no attempt at union as yet; general bealth and strength improving.

The history of the case subsequent to this period need not be detailed at length. About the 8th of July union had taken place in all the bones except the lower jaw. The silver plate, with its gutta percha lining, was retained in its place for nearly seven weeks, being only occasionally removed to be cleaned. The abscess under the chin ended in a fistula communicating with the fracure, but, happily, not penetrating into the mouth; no saliva ever escaped from it. This was the last thing which healed; it remained open long after the fracture, with which it communicated, had united.

There was a remarkable absence of pain during the early part of the case; subsequently, Mr. K- suffered occasionally from severe neuralgic pain in different parts of the face. 
The disfigurement was not nearly so serious as might have been expected from so great an amount of injury. The bridge of the nose, which before the accident was very prominent, was now flattened. The prominence caused by the fracture of the orbital process of the malar bone still remained, and there was a small cicatrix over the left eye. Mr. K- returned to his regimental duty in about four months after the accident.

At the present time, after a lapse of two years, his health is excollent; he never suffers from pain in any of the parts which were injured; and, althongh his features are slightly altered, he is still a remarkably handsome man.

\section{ON THE EMPLOYMENT OF THE ALKALOID OF THE CALABAR BEAN IN PROLAPSUS OF THE IRIS.}

\author{
By THOMAS NUNNELEY, Esq., F.R.C.S.E.
}

Hovina, through the kindness of Mr. Reynolds, of Leeds, been supplied with some of the extract of the Calabar bean dissolved in glycerine, I am instituting a series of experiments as to its action upon the iris in different animals; the result of which, when more complete, I may probably give in your pages. My object just now is not, however, to discuss its purely physiological action, but simply to call attention to the great advantage we may derive by availing ourselves of its undoubted power over the concentric fibres of the iris, by which, in the course of a few minutes, the pupil may be reduced in size to a mere speck, and the whole surface of the iris put upon the stretch; the direction of the force being from the circumference towards the centre of the membrane, precisely as is desired in the cases referred to.

There are few surgeons who do not know how frequently the cornea and anterior margin of the sclerotic are opened by punctured and incised wounds: in women and children by the point of a knife, scissors, knitting-needle, steel pen, and similar instruments; in men by the flying off of a splinter of metal, stone, or other hard brittle substance in the varied mechanic works going on all over the country. And every surgeon also knows how unsatisfactory, in the result, most com. monly such wounds are, occasioning great pain and distress, often tedious confinement and loss of health, and, at the best, in the great majority of cases, resulting in permanent impairment of the eye, more or less considerable, according to the extent of the prolapse of the iris and the severity of the in flammation occasioned by it: a perfect cure being the exception rather than the rule.

Apart, however, from the protrusion of the iris, which almost invariably occurs whenever the cornea or the margin of the sclerotic is accidentally wounded, there is really no reason why these wounds should be so troublesome. Under favourable circumstances wounds of these tissues heal rapidly. Punctured wounds of the cornea and sclerotic, when made by the sur geon, almost invariably heal at once, and not unfrequently the large corneal incision made in extraction of the lens is healed in twenty-four hours. Now, as in the great majority of cases the instrument by which these accidental wounds are inflicted is small and sharp, these are incised wounds in their character; and thus there does not appear to be any reason why, if the iris could only be kept from prolapsing, they should not heal as readily. Of eourse where, as sometimes happens, the offending substance is large and the impelling force considerable, the coats of the eye are lacerated, and the whole ball is contused but, even in these cases, if the lens be neither wounded nor displaced, so highly organised is the ball, and so great its reparative power, that I am convinced, could the iris only be kept in its normal situation, and the lips of the wound in the cornea and sclerotic bo kept in contact, many eyes which are now lost would be saved, and the patients escape great and prolonged suffering.

Many plans have been suggested for disengaging the prolapsed iris, which, though occasionally successful, far more commonly fail. It occurred to me that if the iris could be kept for some hours on the full stretch, by the almost entire contraction of the pupil, it would not prolapse, and thus the corneal wound might heal by the first intention. The result of two cases in which $I$ have employed the alkaloid (for such I presume it to be) of the Calabar bean is most satisfactory, and would quite justify the belief that if a case be seen immediately after the infliction of the injury, before prolapsus has taken place, or, even though this has happened, before adhesion has occurred, the iris may be kept out of the wound, and this will then heal as after a surgical wound. The two cases were as unfavourable as possible, and the results have been far better than I could have anticipated.

T. B_-, aged thirty-three, a boiler-maker, twelve days before $I$ saw him, while driving-in a red-hot rivet, was struck by a small splinter from it, which passed through the left upper eyelid and made a wound in the sclero-corneal junction, through which protruded about a fourth part of the iris. The whole globe was very vascular and irritable; sight was considerably impaired; but the lens did not appear to be implicated, as far as could be judged in the hazy state of the cornea. A small quantity of the extract was blown from the capillary tube, in which it was contained, upon the conjunctiva; within two minutes contraction of the iris began, and in ten minutes the pupil had become small, circular, and central, while the nodule of prolapsed iris had lessened to one.third of its former size. For three hours the effect continued, at twelve hours it had somewhat lessened, and at twenty-four hours had considerably subsided, when another portion of the extract was blown in. The iris at once contracted to the same extent as it had done on the first application, and never again so fully dilated. The pupil remained in a much better position and of a better size. All had been withdrawn from the wound that had not become adherent.

A. S - aged seven years, had the lower margin of the cornea punctured with the point of a knife eighteen days before I saw him. The iris protruded considerably, though not to the same extent as in the man; and the introduction of the alkaloid was at once followed by the partial withdrawal of the iris from the wound and the diminution and centralization of the pupil, but not so completely as in the first case, occasioned probably by the less perfect application of the extract, as the boy was very frightened, struggling and crying, so that the little that did get upon the conjunctiva was washed out by the tears. Twenty.four hours afterwards, when the effect had subsided, a more perfect introduction of the extract caused within fifteen minutes the pupil to become round, central, and. not larger than a pin's head.

In neither case was the least pain or irritation caused; indeed, the effect might be considered soothing, as the vascularity and photophobia materially diminished. No other treatment was adopted for forty-eight hours, in order that the effect might be uninterfered with; and the subsequent progress of both cases was quite satisfactory. The distortion of the pupil and the myocephalon are far less than I have ever seen under similar circumstances, leading to the inference that had adhesion not taken place before the cases were seen the iris would have been restored to its normal condition in each person.

At present the Calabar bean is in the possession of bat few persons in this country; and I am informed even with them the supply is very limited, and can with great difficulty be increased, owing to it being a royal monopoly, which is jealously preserved, but which, doubtless, now that its other than active poisonous power (for which it has hitherto in the country of its production been chiefly if not exclusively valued) is ascertained, will soon be broken down, and a sufficient supply obtained for scientific purposes. In the mean time, I would hope that suffi. cient muy be in the hands of some surgeous who may have the opportunity of trying its effect in preventing the prolapse of the iris in a recent wound of the eyeball.

$$
\text { Leeds, July, } 1863 .
$$

INQUESTs of 1862.-The coroners' returns show that 20,591 inquests were held in England in the year 1862-a number slightly below the average-14,198 on males, and 6393 on females. There were 221 verdicts of murder, 207 of manslaughter, 1284 of suicide, 2429 of "found dead," 157 of death from want, cold, and exposure. The number of inquests held on chilären under seven years of age was $6002-1107$ of the number on illegitimate children; and there were 3239 inquests on infants not more than a year old, of whom 859 were illegitimate. This is the first year in which the children of illegitimate birth have been distinguished in these returns. More than a sixth of the children on whom inquests were held were illegitimate, more than a fourth of the infants not above a year old. The verdicts of wilful murder numbered 124, more than half of which related to children not more than the age of twelve months. 